\title{
Nurses' stories about their interactions with patients at the Holy Family Hospital, Techiman, Ghana
}

\author{
Kwadwo Ameyaw Korsah \\ School of Nursing, College of Health Sciences, University of Ghana, Legon, Accra, Ghana. \\ Email: korsah19@yahoo.com
}

Received 5 April 2011; revised 17 May 2011; accepted 27 May 2011.

\section{ABSTRACT}

Factors, which induced positive nurse-client interactions and barriers to positive nurse-client interactions from the perspective of nurses at Holy Family Hospital, were explored. In all, twelve State Registered Nurses participated in semi-structured interviews. Factors which induced positive nurse-client interaction included availability of adequate time, showing empathy, giving prompt care, considering nursing as a call (spiritual interpretation) and rendering holistic care. Factors which induced negative nurse-client interaction included differences in beliefs between the nurse and the client, perceptions of unfair treatment, payment requirement and processes, issues with clients' relatives, client issues, miscommunications and misunderstandings about treatment needs, coercion, forced dependence, human resource issues, professional nursing issues, issues with work environment, nurse issues, lack of communication and good interaction, and dropping of professional ethics. Suggestions for nursing education, practice and administration have been outlined. Among them is the need to use role-play as a major teaching method for nursing students to develop empathic behaviours so that they can put themselves in clients' situations. This understanding will allow them to practise quality nursing after completing their educational programs. There is also the need for policy makers in nursing to institute measures to hold nurses accountable if they abuse clients or clients' relatives. Lastly, as an important tool, nurses and other health care workers can make use of reflective practice to evaluate their professional interactions with clients and their relatives. This will foster positive nurse-client interaction in future.

Keywords: Nurses; Factors; Positive Nurse-Client Interactions; Barriers to Positive Nurse-Client Interactions; Role-Play

\section{INTRODUCTION}

High quality nurse-client communication is the backbone of the art and science of nursing [1]. It has a significant impact on patient well-being as well as the quality and outcome of nursing care [2], and is related to patients' overall satisfaction with their care [3]. The maintenance of high nurse-patient communication also depends on the nurse and patient. The quality of care in a hospital, has been shown to be influenced by several factors [4] including: inadequate nursing staff, lack of regular water supply on wards, too much nursing documentation, too long waiting time, and lack of specialised nurses. In Ghana, there is crisis in nurse-client communication evidence from four sources. These are personal observation, anecdotes from client and their families, media reports, and official health reports.

\subsection{Problem Statement}

There is public outcry about the behaviour of nurses during interactions with their clients. The crisis in nurseclient interactions remains a serious problem in Ghana, despite criticism and concern expressed by the public, Ghana Ministry of Health, Ghana Health Service, and the Nurses and Midwives Council for Ghana. Personally, as a researcher, I have observed nurses who were verbally abusing clients and their relatives in the hospital where I practised. I have also observed nurses who pay little attention to their clients' requests. In one instance a nurse told a male client in the researcher's ward that, "If you could treat yourself at home, you would not have come here to see us, so keep quiet ...” Such behaviours on the part of nurses are unfortunately a common occurrence at the hospital. It is important and helpful to note that these negative interactions between nurses and their clients do occur at any time irrespective of either early after admission or are more frequent after a long period of hospital care. It is also important to know that doctors do their wards rounds once per day and are available to see seriously ill patients only on call basis and so some 
of these poor nurse-client interactions may happen during their absence.

In an attempt to find more about this problem and what could be done to help reverse the trend of negative nurse-client interactions, the Ministry of Health and other stakeholders in the health sector (e.g., Ghana Prevention of Maternal Mortality,

GPMM) have organized workshops and in-service training for various categories of nurses. It is wondered whether those training activities and programmes are yielding the expected results, especially in the area of nurse-client interactions. It was based on these that the following research questions were posed to address the problem.

1) What factors facilitated positive nurse-client interactions?

2) What factors were barriers to positive nurse-client interactions?

\subsection{Purpose of the Study}

The purpose of the study was to describe factors that facilitated or enhanced effective nurse-client interactions and factors that were barriers to facilitating effective nurse-client interactions.

\subsection{Significance of the Study}

Identifying factors believed to facilitate positive interactions between nurses and their clients or clients' families as well as barriers to these positive interactions will do much to promote the well being of those seeking health care in Ghana. The increased insight about nurse-client experiences in this study should help nurses and other health care workers establish positive and appropriate therapeutic relationships with their clients. Study findings can also be used to inform decision makers in health and nursing about what needs to be done to improve communications patterns between health providers and their clients. Areas for future research in nurse-client interactions were also identified. It would also be of help to other educational institutions especially those involved in health education, health research and health training programmes.

\section{LITERATURE REVIEW}

In a qualitative study, Morrison [5] described nurses' perceptions of the concept of caring as central to nursing practice. It involves meeting needs of patients in nurseclient interactions. In all 7 categories emerged from the analysis that provided a detailed description of caring. These included interpersonal approach, clinical work style, concern for others, time management, attitudes, personal qualities and level of motivation. Other descriptions by the nurses related to the physical aspects of care.

Positive interpersonal relationships between the nurse and the client were considered to be caring and caring for clients was optimum when nurses were motivated in the form of rewards by managers. Caring also depended on the skill and the competence of the nurses. Competent and skilled nurses delivered high quality nursing care to clients at the right time. Caring practices of these nurses were also demonstrated by positive facial expressions and closeness to clients.

In another study on caring and interacting with patients, Younge and Molzahn [6], using a grounded theory method interviewed 18 nurses who were identified as exceptional in caring from two regions in Western Canada. The core process was giving and involved gift giving, teaching, preserving dignity, caring with and for co-workers, being truly present, finding a way, being responsible, choosing, and vulnerability. It was observed that there were many gifts that the nurses gave or re-quested for their clients. These included night-gowns, cloth bags with holders for insulin syringes, medical equipment, used clothes, bread and having breakfast together. It was noticed that all the nurses talked about teaching their clients. The nurses explicitly outlined the interventions they used to heal their clients and then ensured that they taught clients about the interventions. The nurses saw teaching as happening anytime and anywhere. There was recognition on the part of these nurses that a client must be ready to learn.

Nurses in their study described a number of situations where they went to lengths to preserve client dignity. They did not challenge clients who made mistakes and accepted the clients for who they were. The nurses talked about their nurse-client relationships with coworkers. Some co-workers were supportive and helped the nurses provide exceptional care where as others had to be taught how to give care. Co-workers were mentored or coached by the nurses to give high quality care. The caring nurses were truly present with clients and families. It was noticed that they were thoughtful, considerate, empathic, decisive and practised holistically. They did not view the clients as being in isolated from their families, and in turn, viewed the families as part of the community. They validated their perceptions using therapeutic touch and physical assessment. They shifted their thoughts to become conscious of what the clients were experiencing. For the nurses to be truly present that they needed to know their clients. They worked to find solutions to each problem, which at times involved providing hope in hopeless situations. These nurses also expected accountability from their clients and were very clear about their roles and responsibilities.

Nursing researchers generally agree that the mainte- 
nance of patient dignity is highly valued by clients. They also agree that a lack of dignity may lead to poorer health outcomes.

A phenomenological investigation of dignity as experienced by nurses during their interactions with clients was conducted [7]. Nurses were asked to describe experiences where client dignity had been maintained and where it had been compromised. The interviews were unstructured and experiential in nature. In all four (4) nurses were interviewed.

It was noted that nurses need to respect clients and accord them privacy. It was also reported that clients should not be seen as an object or body alone. Clients needed to be seen to possess an innate right to be treated with dignity and respect in all situations and at all times whether the client was conscious or unconscious, alive or dead. Respect would appear to these nurses to mean treating a person with respect to their personhood, that is, the nature of the person, their feelings, their individuality and their wishes.

The body and its treatment was a central theme in nurses' accounts. It was noticed that much about client dignity revolved around the exposure of the body and the gaze of others. Nurse's spoke of the importance of screening the bed area while performing procedures and covering the parts of the client's body that did not need to be exposed while washing the client or performing other aspects of care. It was also identified that protecting patients from involuntarily viewing other clients in undignified situations was another means to maintain the dignity of all concerned. Nurses believed that clients need space and privacy to express emotions and share with family members. Dignity also meant having some forethought about the emotional reaction that clients might experience if procedures, information or diagnoses were not explained adequately or without thought about how best to help clients manage the emotional impact of such things.

The nature of care provided and interpersonal aspects of caring emerged as key quality issue for clients in Attree's [8] study. Good quality care was characterised as individualised, patient focused and related to need; it was provided humanistically through the presence of a caring relationship by staff who demonstrated involvement, commitment and concern. Positive comments were made about staff who provided care where clients were the central focus. Staff who showed an interest in, feeling for and value of clients as individuals provided good quality care. Individualised care was also viewed as good care. Showing respect for individual's rights, dignity and privacy were commended. It was also observed that clients who were included and involved in decisions and choices about their care and treatment ac- knowledged this as quality care. Nurses who anticipated clients' care needs were specifically praised, as were those who gave help freely and were willing and prepared to do anything.

Good quality care encounters were also characterised as being practised by nurses who were friendly, warm, sociable and approachable and who developed a bond or rapport as opposed to adopting more formal, distant traditional 'professional' staff-client relationships. Nurses who encouraged social conversation, social relationships and contact with clients were commended. Social contact with nurses was seen as the way to form bonds and friendly social relationships, which enabled them to feel capable. Quality care was also acknowledged when nurses showed an interest in clients as people. Nursing practices, which gave clients this impression, included nurses listening to and talking with them. Knowing the client was not seen as a single process; patients appreciated nurses who shared personal details about themselves and their family. Nurses who got to know clients as people were seen to encourage more social contact between clients and their relatives. Attree [8] identified nurses who showed good humour as delivering quality nursing care.

Open communication was also seen as one of the most important characteristics of good quality care, as well as being necessary for the development of good client-nurse relationships. Engaging in conversation with clients, both talking with and listening to them is seen as essential for good and effective communication and understanding. Clients see effective communication as being necessary for nurses to find out about their needs and problems as well as to explain what is going on and to provide information and advice.

Nurses who demonstrated a caring attitude evidenced by showing kindness, concern, compassion, sensitivity and sympathy were identified as giving good quality care. It was also observed that nurses who had a calm, gentle, kind and unhurried approach to client care were recognised as good nurses. Attree [8] reported that clients and relatives were comfortable with nurses who were available, accessible, and approachable and these were demonstrated through nurses who had time for clients and relatives. These are the type of nurses clients require, "who come when called, come back when they say and are there when needed or wanted".

\section{METHODOLOGY}

The study was conducted at the Holy Family Hospital, Techiman, Ghana. Techiman is a town in the Brong Ahafo Region of Ghana. It is a newly created municipality with a census of 131,269 [9]. Inhabitants are predominantly farmers and traders. Holy Family Hospital is 
a Roman Catholic Mission hospital and serves as a municipal hospital for Techiman. The hospital has a bed capacity of 140 and the total number of nurses is 65 . Most of the clients who attend Holy Family Hospital are farmers and traders. The various nursing units in the hospital include paediatrics, medical, surgical, emergency, maternity and labour wards. The other units are the outpatient and the primary health care departments.

The spectrum of medical cases which necessitate admissions in this hospital include pneumonia, hypertension, diabetes mellitus, typhoid fever, malaria, and meningitis to mention a few. The nursing population includes 30 State Registered Nurses (SRN); 31 Enrolled Nurses (EN); 3 Community Health Nurses (CHN) and 1 Public Health Nurse (PHN). A qualitative exploratory descriptive design was used for this study.

\subsection{Sample and Sampling Procedure}

A convenience or volunteer sample of State Registered Nurses who worked in either outpatient or in-patient departments at Holy Family Hospital were recruited for the study. Nurses who had worked for a minimum of 3 years at the hospital and were willing to tell about their experiences were eligible for inclusion in the study. By working for 3 years, participants had ample opportunity to observe and participate well in nurse-client interactions in the hospital. In addition, all participants were full time registered nurses in the hospital and had their nursing training in Ghana. The 12 State Registered Nurses who participated in this study were all Ghanaians. Their ages ranged between 26 and 49 years. Four were males and eight were females. They had worked in the hospital for 3 to 27 years. Each nurse received a letter that was personally addressed to her. The purpose of the study was briefly explained in the letter and an invitation was extended to each participant to attend one of two information meetings where detailed information about the purpose and objectives of the study were given. It was explained that the interviews would be recorded and that they were free to opt out if they did not want to continue. Consent form was then offered. If the potential participant read the information letter and signed the consent form, the one was considered for the study.

\subsection{Data Collection}

Data were collected by interviewing participants. The interview consisted of guiding questions with underlying prompting questions, which were used if information was not forthcoming. In the study the participants were asked to describe instances of positive and negative interactions with patients/clients to discuss factors that facilitated or reduced each type of interaction.

\subsection{Data Analysis}

Data collection and analysis proceeded simultaneously. After each interview, the tape was transcribed manually by the researcher. The accuracy of the transcripts was checked by listening to the audiotape and reading the transcripts simultaneously. The data was coded by hand using different colours. In all, 10 major files were created based on the colour codes. A print out of these files was also made and categories were formed from them. Finally, higher-level categorisation was constructed from the initial categories. That is, categories which fit into common files were also brought together to form final and major categories. The analysis of the interview transcripts was guided by content analysis, which has been identified as appropriate for analysis of interviews [10].

\section{FINDINGS}

Findings of the study were grouped under two main headings with their respective subheadings.

\subsection{Facilitative Factors for Effective or Positive Nurse-Client Interactions}

\subsubsection{Availability of Time}

The amount of time available for nursing care is found to influence the type of interaction and amount of care given. Many of the activities undertaken by nurses are dependent on availability of sufficient time in which to execute them. In this research study, various reasons were given by 9 (75\%) nurses for the availability of time mainly relating to the number of nurses on duty and client workload. Having sufficient time to meet clients' needs was considered a major factor facilitating positive nurse-client interaction. A nurse stated:

"So... I had time; I was able to listen to the client, found some solution to the problem, involving the husband to be supportive ... because I had time for the client as an individual”.

\subsubsection{Empathy}

Most 10 (83.3\%) of the nurses in this research study described their interactions with clients as positive when the nurse was empathic. One of the nurses said:

"I kept myself in his shoes "supposing I am sick and I don't have anything to eat. My wound is draining, the gauze is soiled and nobody to dress it, how will I feel?" So because of that I had to take that step to help the client".

Another nurse also said:

"I always see and put myself in their place; I would also be reacting in the same way, so I put myself into the situation of the client... But if you have not neglected them and have put yourself in their shoes, you will realise how important they are. We provide them a place to 
eat... and also give them a sheet to lie on..."

\subsubsection{Prompt Treatment}

All (12) (100\%) nurses defined positive nurse-client interaction as when clients received prompt nursing care. One of the nurses stated:

"Prompt care means the right person [nurse] seeing the client at the right time and giving the appropriate nursing care, including medication, promotes positive nurse-client interaction".

In the process, nurse recognises the client as an individual with dignity and deserves to be respected.

\subsubsection{Rendering Holistic Care}

Six (6) $(50 \%)$ participants perceived that they had positive interactions with clients and their relatives when they were able to render holistic care. A nurse stated:

"When we are treating the patient, we don't limit ourselves to the disease alone.... We treat him as a social being with relations back home..."

Another one said:

"I was very proud of myself. I felt proud because I was able to... at least, through a client I have been able to educate sort of a whole family, because when I got to the house, they all, almost everybody was around and I educated them, so they were all very happy".

\subsubsection{Nursing as a Call}

Five (5) (41.6\%) research participants perceived nursing as a call. These participants explained that nurses do not have to work for money alone but they must see nursing as a call to help the needy and that nurses who perceive nursing as a call are likely to encounter positive interactions and relationships with clients and their relatives. A participant said:

"If it is because of money, nurses will not work, because the service that we are rendering, it doesn't match the money that we receive, but we are only doing it as a call. We are only doing service to God. It is not because of money".

\subsection{Barriers to Positive Nurse-Client Interactions}

\subsubsection{Differences in Beliefs between Nurses and Clients}

One source of conflict between nurses and their clients was a difference in beliefs about western and traditional medicine. A major factor was reported by 10 (83.3\%) nurses at the Holy Family Hospital. In one instance, a participant stated:

"Whatever that you tell the client, he will not listen because... he believes in traditional medicine, sometimes the relatives will come and tell you that they prefer a local healer, in spite of having explained to them the implications of their actions."

\subsubsection{Perceptions of Unfair Treatment}

A conflict occurs when client perceives that a nurse has treated her unfairly. This tends to generate poor interactions between the two. Perceptions of unfairness featured prominently in this study. In some cases the nurses reported that they provided priority services to patients with more serious conditions and were insulted by clients with less serious conditions who wanted prompt care. Using their professional judgement 9 (75\%) nurses reported that they thought critically ill clients were more in need of urgent attention. A nurse quoted her client as saying:

"Oh we can't sit here and somebody will just come and take our place"

\subsubsection{Payment Requirements and Processes}

Ten (10) (83.3\%) participants mentioned that the payment requirements and processes in the hospital interfered with the nurse-client interactions and relationships. In some instances the clients refused to be admitted even when it was strongly advised. Such professional advice was resisted by the clients for financial reasons. One of the nurses quoted her client as saying:

"My husband is not in town; if my child goes on admission, who will help me to pay for the bill?"

\subsubsection{Conflicts with Clients' Relatives}

Nurses' interactions with clients' relatives featured prominently in negative nurse-client interactions. Often nurses reported confrontations with clients' relatives. Non-observance of visiting hours by clients' relatives resulted in negative interactions between nurses and clients' relatives. Seven (7) (58.3\%) nurses complained that visitation by relatives outside the stipulated visiting hours disrupted their work, disturbed other clients and threatened their privacy. Relatives' failure to observe visiting hours elicited negative responses from the nurses. A nurse stated:

"We tried to send them out because they came earlier than the scheduled visitation hour. We told them to leave as we were then doing ward rounds but they refused to leave the ward."

\subsubsection{Client Issues}

At times clients do not do what is recommended or required by the nurses. One (1) (8.3\%) of the participants mentioned that a client found fault with everything the nurse did for her. She stated:

"So I had this client in my ward and I can really say that she was one of the very, very difficult patients I have ever come across in my nursing career because no matter what I did for this woman, she always found fault. If she rang the bell calling you and if you didn't appear within a minute or two it was all hell." 


\subsubsection{Miscommunications and Misunderstandings about Treatments Needs}

Negative interactions between nurses and their clients occurred when information given by nurses was not properly understood. Clients misunderstood what the nurses said and this resulted in an adverse health outcome.

For example, one (1) (8.3\%) participant reported that a client did not receive the right information from the nurse about his treatment needs and took his medication at the wrong time which later resulted in poor interaction between the nurse and the client.

\subsubsection{Coercion}

In their interactions with clients, nurses applied force to make their clients comply with instructions. Nurses were perceived as the powerful and the clients as the powerless. This unequal relationship was seen as a barrier to effective nurse-client interactions. Some of the nurses used their power in an unacceptable manner by commanding their clients to comply with whatever instructions they issued. In this sort of relationship, the client was powerless and had to "trust and obey" the nurse in all situations. Nine (9) (91.6\%) nurses in their interactions with clients demonstrated a hierarchical relationship. For example, a nurse was observed shouting authoritatively at a client:

“Madam would you mind your speech".

\subsubsection{Forced Dependence}

Forced dependence is defined, as use of force by the nurse to condition the client. In situations where the nurses perceived the clients as difficult, four (4) (33.3\%) nurses applied forced dependent measures to compel their clients to obey orders. A nurse whose 'orders' were disregarded by a lady in labour was quoted as saying:

"But we told her it was very dangerous for her and for the foetus. She couldn't understand, so we told her, if you don't help us we are going to tie you up".

\subsubsection{Human Resource Issues}

There were human resource factors, which undermined effective nurse-client interactions. Staffing shortages were such that nurses did not have enough time for their clients. Few nurses coupled with high workload lead to inadequate interaction with clients. Ten (10) (83.3\%) nurses attributed the shortage of nurses to the exodus of nurses to other countries like the United Kingdom and the United States of America. Reflecting on nursing shortages, one participant stated:

"We don't have sufficient nurses, I don't think it is good enough for two nurses to work on twenty clients during a shift. I don't think it is proper. That is happening and in the night, a nurse will attend to about thirty children with one ward aide. You can well imagine the workload and the frustration that goes with it under such circumstances."

\subsection{Professional Nursing Issues}

Task orientation and organisation made it difficult for nurses to give holistic care to their clients. All the twelve (12) $(100 \%)$ nurses mentioned that they had to combine tasks in order to complete them and that thwarted their efforts to render holistic care to clients. The nurses were busy and not able to communicate effectively with their clients. They have become so habituated to the situation that they forget to teach and communicate with clients even when they are less busy.

\subsubsection{Work Environment}

Managerial influences to a large extent determined the type of interactions between nurses and their clients. Lack of concern about staff by managers interfered with nurse-client interactions. Five (5) (41.6\%) nurses reported that managers were unsupportive and unresponsive to nurses' needs. Many of the nurses who left the hospital sought employment elsewhere in Ghana. One of the nurse stated:

"Yeah, if legitimate requests to the officials are treated with contempt, confusion will always reign."

\subsubsection{Nurse Issues}

Nurses who stay in rented premises outside the hospital cannot effectively respond to emergency calls. Stress, tiredness, frustration and long working hours without a break affects nursing attitudes, which has serious negative implications for clients and their relatives. The nurses noted that stress and overwork lead to frustration and anger in the work place. Personal life issues of some of the nurses affected their interactions with clients. In some case, seven (7) (58.3\%) nurses identified personal issues as justification for how nurses interacted with their clients and the families of their clients. As one of the nurses stated:

"I must be very frank here, some nurses carry along with them their personal problems to the work place, so just a slight provocation, they are always annoyed".

\subsubsection{Lack of Communication and Good Interaction}

Participants perceived their failure to provide information to their clients as negative. Lack of explaining disease conditions, explaining institutional processes resulted in negative nurse-client encounters. According to all the twelve (12) (100\%) participants, nurses who were perceived to have ignored their clients were not highly regarded by their clients.

\subsubsection{Ignoring Professional Ethics}

Although professional ethics is part of professional nursing curricula, lapses according to the participants led 
to negative nurse-client interaction. These lapses represented a breach of clients' rights and constituted neglect of clients. Negligence by nurses or failure to take proper care of clients by nurses emerged strongly in this research. All the twelve (12) (100\%) participants acknowledged this fact. As one nurse said:

"Half of negative nurse-client interactions are caused by negligence of duty".

Other examples of lapses in professional ethics occurred when research participants reported moving their clients up and down between the emergency room and the outpatients department to look for their doctors and "sacking" or expelling clients when they did not report to the clinic on time.

\section{DISCUSSION AND CONCLUSIONS}

From this study having sufficient time to meet clients' needs was considered a major factor supportive of positive nurse-client interactions and relationships. Eighty five percent (85\%) of nurses in O’Malley [11] work indicated that they were able to meet clients and their families' needs due to availability of time. According to Irurita [12], an effective nurse-client relationship was considered to be central to quality nursing and this required time. McNamara [13] supported clients’ needs had to be met, whether they were conscious or unconscious. The nurses in her study described the essential structure of caring as the establishment of a human care relationship and provision of needs of clients. Dryden [14] acknowledged that there is need for healthcare institutions to care for their nurses and health professionals' private and professional needs in order to render quality care. Redfern and Norman [15] acknowledged that good facilities and adequate resources in terms of workforce, equipment and supplies, support services and time to do a good job were identified as important for nurses to give comprehensive nursing care. The analysis of the experience of nurses highlighted a theme of “Management Environment”. The respondents were enthusiastic about promoting horizontal relationships between nurses and managers to find solution to problems affecting the institution. The nurses were also concerned about the institutional education and accommodation policies. These observations from the study are supported by other investigators who acknowledged that a major predictor of job satisfaction for nurses was nursemanager collaboration [16]. In this Ghanaian study when the nurse participants were empathetic, they described their interactions with clients as positive. Empathic nurses absorb the negativity of their clients [17]. Most of the nurses said effective communication occurred when they listened with sympathy and used appropriate non-verbal behaviours.
Geanellos [18] studied friendliness and friendship within the nurse-client relationship and identified nurses' who smiled, joked, spoke in warm tones of voice and showed interest in clients as promoting nurse-client communication.

Redfern and Norman [15] found that exceptional nurses are those who raise clients' morale by responding promptly to their treatment needs and promoting their autonomy. In this research, five (5) (41.6\%) nurse participants perceived nursing as a call which served as a catalyst for them to interact positively with clients. This finding is in line with Kritek [19] who acknowledged that nursing is a call, and that nurses who are able to recognize this fact in the course of client care, get to the roots of nursing care. O'Brien [20] also found a different dimension of nursing as a call. She acknowledged that nurses are called to lay down their lives for clients as Jesus Christ died on the cross for sinners. In this study conflict arose over and treatment choices. Interpersonal conflict occurs between individuals, especially between people who differ with regard to beliefs, values and goals [21]. Hupcey [22] emphasizes that teamwork and cooperation between nurses and family members benefit the client. However, nurse participants' interactions with clients' relatives strongly influenced the development of negative interactions in this Ghanaian study. Non-observance of visiting hours by relatives and family disagreement with the choice of treatment was the source of much conflict. In this Ghanaian study, nine (9) (91.6\%) participants used their power in unacceptable ways. The literature is replete with research on the power differential between nurses and clients. The unequal relationship is a significant barrier to effective nurse-client interactions [23]. Staffing problems did not allow nurses to have enough time for their clients and their clients' families in this study. Meilman [24] also acknowledged that to provide first-rate services to students and other health consumers in and around a large university hospital, the university health service needs best possible staff.

A task-orientation toward providing nursing care made it difficult for nurses to give quality care to clients in this study. The nurses were always busy and unable to communicate with their clients effectively. The majority of nurse-client interactions are related to tasks and routines [25]. Lapses in professional ethics and adherence to professional nursing standards affected nursing interactions with clients. Findings from this study support another African study where pregnant women were found to be abused by midwives in an obstetric unit in a South African hospital [26]. Midwives in the hospitals were described as rude, inhuman and uncaring and reported to be speaking to clients harshly for breaking the rules in the midwife unit. In conclusion, from the perspectives of 
nurses factors that facilitate positive nurse-client interactions and as well as those that are barriers to positive interactions were illuminated.

\section{STUDY LIMITATIONS}

It is difficult to assess the degree to which participants may have felt obliged to participate or respond to questions in a particular way. However with the researcher's background as a nurse and previous experiences in nurse-client interactions, participants were probed extensively and deeply about their responses in an effort to reduce bias.

\section{RECOMMENDATIONS}

The findings of this study and their analyses provide some direction.

1) Nurses need to be prepared to put themselves in clients' situations. This will enable them practice and render good quality care to their clients and their families. Through role-play nursing students will understand how to put themselves in clients' situations. In view of this, curriculum for nursing education needs to have role-play or simulation exercises as a major method of teaching students how to function appropriately in client encounters.

2) Workshops that address client's total needs, reflective practice with the support of managers, and incentives are possible interventions that could bring about changes in nursing attitudes and behaviours.

3) The findings, especially with regard to the nurses' poor attitudes to clients and their families suggest that a code of ethics needs to be enforced, using disciplinary procedures if necessary, so that nurses are aware that abuse of clients is sanctioned by their professional organization.

4) Finally, nurses should know that as health professionals their beliefs should not affect their ability to establish positive interactions with clients and clients' families. They can explain their professional point of view in a therapeutic manner while hearing and valuing their client's point-of-view.

\section{REFERENCES}

[1] Thompson, I.E. (1994) Nursing ethics. 3rd Edition, Appleton \& Lange, Tokyo.

[2] Richmond, I. and Roberson, E. (1995) The customer is always right: patients' perceptions of psychiatric nursing action. Journal of Nursing Care Quality, 9, 36-43. doi:10.1097/00001786-199501000-00008

[3] Meehan, T. (1995) Development of an instrument to assess consumer satisfaction with mental health services and treatment. House Publication, Sidney.

[4] Mensah, K. and Opoku, S. (1994) Report on quality assurance. Wa Hospital, Ghana.
[5] Morrison, P. (1991) The caring attitude in nursing practice: A repertory grid study of trained nurses' perceptions. Nurse Education Today, 11, 3-12. doi:10.1016/0260-6917(91)90118-T

[6] Younge, O. and Molzahn, A. (2000) Exceptional non-traditional caring practices of nurses. Scandinavian Journal of Caring Sciences, 16, 399-405. doi:10.1046/j.1471-6712.2002.00102.x

[7] Walsh, K. and Kowanko, I. (2002) Nurses' and Patients' pereceptions of dignity. International Journal of Nursing Practice, 8, 143-151. doi:10.1046/j.1440-172X.2002.00355.x

[8] Attree, M. (1999) Patients' and relatives' experiences and perspectives of 'good' and 'not so good' quality care. Journal of Advanced Nursing, 33, 456-466. doi:10.1046/j.1365-2648.2001.01689.x

[9] Ghana Statistical Service. (2000) National Population and Housing Census, Ghana.

[10] Strauss, A. and Corbin, J. (1990). Basics of qualitative research: Grounded theory, procedures and techniques. Sage Publications, Newbury.

[11] O’ Malley, P., Favaloro, R., Anderson, B., Anderson, M.L., Siewe, S., Keefer, N. and Riddle, K. (1991) Critical care nurse perceptions of family needs. Heart and Lungs, 20, 189-201.

[12] Irurita, V.F. (1999) Factors affecting the quality of nursing care: The patient's perspective. International Journal of Nursing Practice, 5, 86-94. doi:10.1046/j.1440-172x.1999.00156.x

[13] McNamara S.A. (1995) Perioperative Nurses' Perceptions of caring practices. Association of Preoperative Registered Nurses Journal, 61, 337-388. doi:10.1016/S0001-2092(06)63890-8

[14] Dryden P. (2003) Introduction to Nurses House. Nurses House, April 2003.

[15] Redfern, S. and Norman, I. (1999) Quality of Nursing care perceived by patients and their nurses: An application of the critical incident technique, part 2. Journal of Clinical Nursing, 8, 414-421. doi:10.1046/j.1365-2702.1999.0288b.x

[16] Larrabee, J.H., Janney, M.A, Ostrow, C.L, Withrow, M.L., Hobss, G.R. and Burant, C. (2003) Predicting Registered Nurse Job satisfaction and Intent to Leave. Journal of Nursing Administration, 33, 271-283.

[17] Bowles, N., Mackintosh, C. and Torn, A. (2001) Nurses' communication skills: An evaluation of the impact of solution-focused communication training. Journal of Advanced Nursing, 36, 347-354. doi:10.1046/j.1365-2648.2001.01979.x

[18] Geanellos, R. (2002) Exploring the therapeutic potential of friendliness and friendships. Contemporary Nursing, 12, 235-245. doi:10.5172/conu.12.3.235

[19] Kritek, P.B. (2001). Rethinking the care environment: Luxury or necessity? Advanced Practice in Acute Critical Care Clinical Issues, 12, 336-344.

[20] O’ Brien M.E. (2003) Navy Nurse: A call to lay down my life. Journal of Christian Nurses, 20, 32-33.

[21] Northouse P.G. and Northouse L.L. (1992) Health Communication: Strategies for Health Professionals.2nd Edition, Appleton \& Lange, Connecticut.

[22] Hupcey, J.E. (1999) Looking out for the patient and ourselves - the process of family integration into the ICU. 
Journal of Clinical Nursing, 8, 253-262. doi:10.1046/j.1365-2702.1999.00244.x

[23] Parker, I., Georgaca, E., Harper, D., Mclaughlin, T. and Stowel S.M. (1995) Deconstructing psychopathology. Sage Publications Ltd., London.

[24] Meilman P.W. (2001) Human resource issues in university health services. Journal of American College of
Health, 50, 43-47.

[25] Holyoake, D. (1998) Observing nurse-patient interaction. Nursing Standard, 12, 35-38.

[26] Jewkes, R., Naeemah, A. and Zodumo, M.V.O. (1998) Why do nurses abuse patients? Reflections from South African Obstetric Services. Social Science and Medicine, 47, 1781-1795. doi:10.1016/S0277-9536(98)00240-8 